\title{
Direct fabrication of well-aligned free-standing mesoporous carbon nanofiber arrays on silicon substrates
}

Kaixue Wang, Wenhua Zhang, Richard Phelan, Michael A. Morris and Justin D. Holmes*

Department of Chemistry, Materials Section and Supercritical Fluid Centre, University

College Cork, Cork, Ireland and Centre for Research on Adaptive Nanostructures and Nanodevices (CRANN), Trinity College Dublin, Dublin 2, Ireland

\section{Supporting information}

\section{The preparation of the phenolic resin and precursor sol}

The phenolic resin was prepared from the reaction of phenol with formaldehyde in a base-catalyzed process following a previously reported procedure (Meng, Y. and Zhao, D. Y. et al., Chem. Mater. 2006, 18, 4447-4464.). In a typical procedure, $0.61 \mathrm{~g}$ of phenol was melted at $40-42{ }^{\circ} \mathrm{C}$ in a flask and mixed with $0.13 \mathrm{~g}$ of $20 \mathrm{wt} \%$ sodium hydroxide $(\mathrm{NaOH})$ aqueous solution under stirring. After $10 \mathrm{~min}, 1.05 \mathrm{~g}$ of formalin (37 wt \% formaldehyde) was added dropwise below $50{ }^{\circ} \mathrm{C}$. Upon further stirring for $1 \mathrm{hr}$ at $70-75{ }^{\circ} \mathrm{C}$, the mixture was cooled to room temperature. The $\mathrm{pH}$ was adjusted with $0.6 \mathrm{M} \mathrm{HCl}$ solution until it reached a value of 7.0, and water was removed by vacuum evaporation below $50{ }^{\circ} \mathrm{C}$. The final product was dissolved in $5 \mathrm{~mL}$ of ethanol.

The synthesis composition of the precursor was in the range of phenol/formaldehyde/NaOH/F127 (molar ratio) $=1: 2: 0.1: 0.010-0.015$. In a typical preparation, $1.0 \mathrm{~g}$ of F127 was dissolved in $20.0 \mathrm{~g}$ of ethanol. Then $5.0 \mathrm{~g}$ of the sol precursors in ethanol solution was added. After stirring for $10 \mathrm{~min}$, a homogeneous solution was obtained.

\section{The preparation of mesoporous carbon nanofibre arrays in AAO}

A glass tube with diameter of about $18 \mathrm{~mm}$ was first attached onto the surface of silicon wafer using mounting wax (Allied High Tech Products, INC. 71-10040). A 
piece of AAO membrane together with $0.3 \mathrm{~mL}$ of the above precursor sol was put into the tube. The sol infiltrated the pores of the AAO membrane and changed to a gel during the aging process at room temperature and at $60{ }^{\circ} \mathrm{C}$. The gel infiltrated AAO membrane was calcined at $600{ }^{\circ} \mathrm{C}$ in a $\mathrm{N}_{2}$ atmosphere for approximately 3 hrs to decompose the surfactant and carbonize the mesoporous walls.

\section{The drying process in supercritical $\mathrm{CO}_{2}$}

Firstly, the alumina membranes were removed by treatment with a $6 \mathrm{M} \mathrm{HCl}$ solution for more than $24 \mathrm{~h}$ rs. After washing several times with distilled water and then ethanol, the sample was quickly transferred to a $20 \mathrm{~mL}$ stainless steel cell filled with ethanol. The ethanol was replaced by liquid $\mathrm{CO}_{2}$. After the cell was completely filled with liquid $\mathrm{CO}_{2}$, the temperature of the cell was increased to $60{ }^{\circ} \mathrm{C}$ and the pressure to approximately 150 bar. The samples were maintained at such condition

for about 1 hr. Finally, the supercritical $\mathrm{CO}_{2}$ was transformed to its gas phase by decreasing the pressure at the same temperature.

\section{Characterization}

The morphology of the arrays of carbon nanofibres was characterized by scanning electron microscopy (SEM) performed on a JEOL JSM-5510 scanning microscope operating at $10 \mathrm{kV}$. Transmission electron microscopy (TEM) images were collected using a JEOL 2000EX microscope operated at $200 \mathrm{kV}$. Samples for TEM were prepared by the following method: 1) the AAO membranes were dissolved in a $2 \mathrm{M}$ $\mathrm{NaOH}$ solution to release the embedded mesoporous carbon fibres; 2) top views were prepared by dimple grinding followed by Ar ion polishing. 
Figure S1 SEM images of carbon nanofibres dried in air after dissolving of the alumina membranes. Without supercritical $\mathrm{CO}_{2}$ treatment, all of the nanofibres become entangled to form bundles due to surface tension forces.

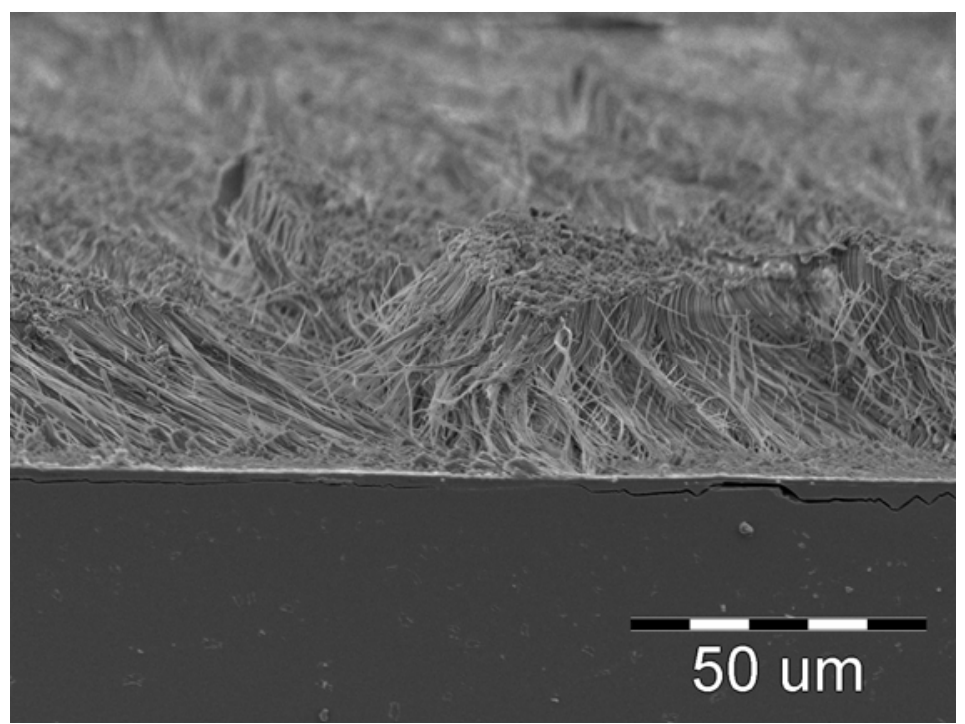

Cross-section view



Top view 
Figure S2 Low magnification top-view SEM image of arrays of mesoporous carbon nanofibres on a silicon wafer prepared by the sc- $\mathrm{CO}_{2}$ drying process.

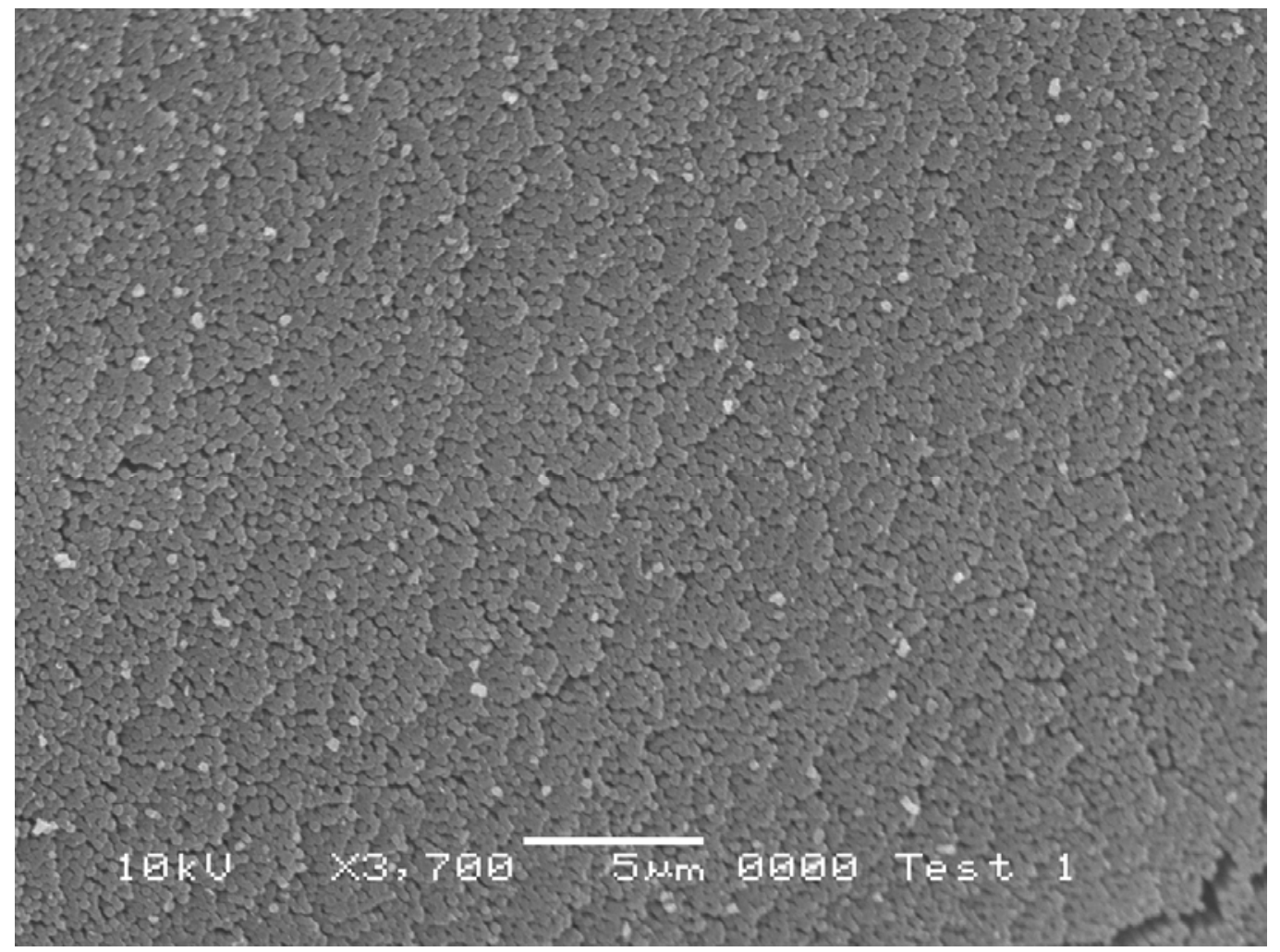


Figure S3 Low magnification TEM image of mesoporous carbon nanofibres released by dissolving an AAO membrane in a $\mathrm{NaOH}$ solution. The saw-shaped observed edges in some of the nanofibres vividly reflects the inner surface morphology of porous channels of the AAO membrane.

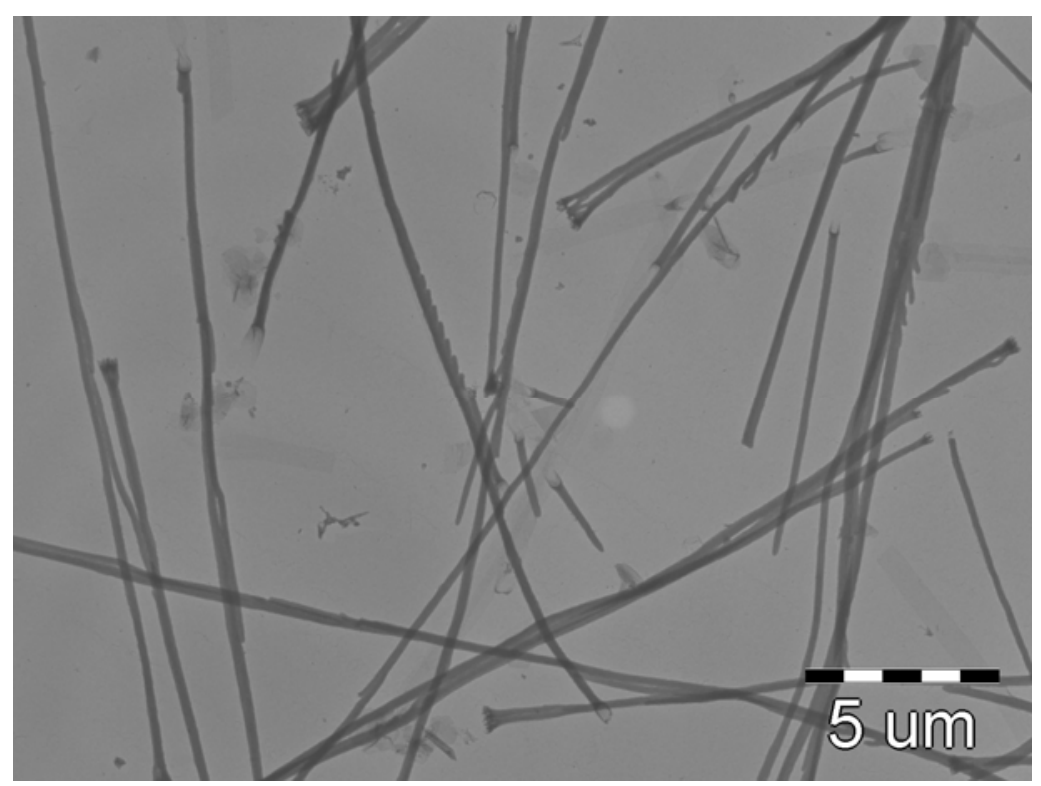


Figure S4 $\mathrm{N}_{2}$ adsorption-desorption isotherms of pure mesoporous carbon fibers confirming their mesoporous nature. BET surface area and total pore volume are $907.3 \mathrm{~m}^{2} \mathrm{~g}^{-1}$ and $1.32 \mathrm{~cm}^{3} \mathrm{~g}^{-1}$, respectively. The $\mathrm{BJH}$ absorption average pore diameter is approximately $5.0 \mathrm{~nm}$, which is in good agreement with the TEM observation.

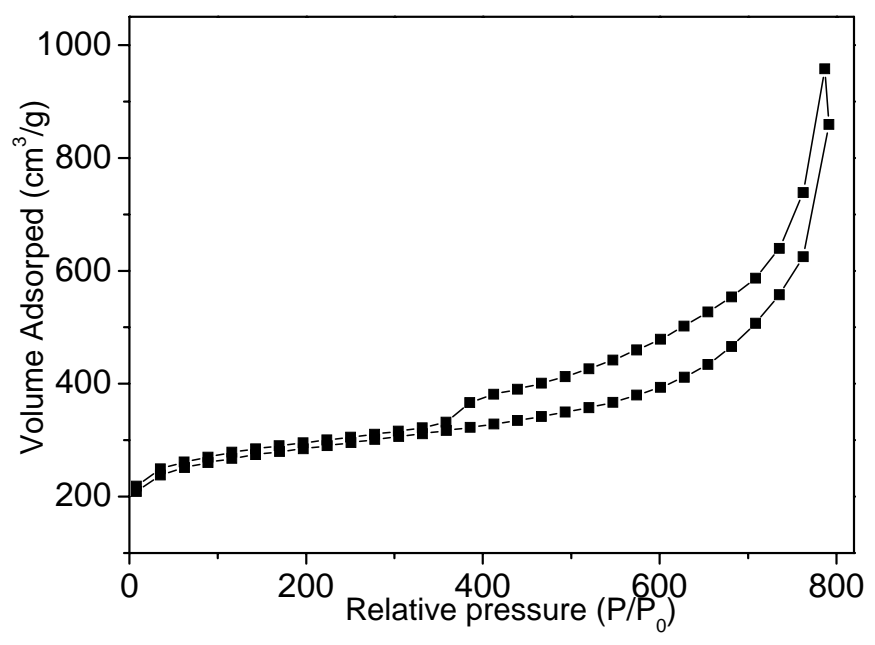

